ration may have contributed. The tumour remained nearly stationary, from its first diminution after the operation, for some time, but rather on the decrease.

He was kept in bed several weeks, and pressure applied over the tumour and limb; when he got up he walked well, and was discharged on the 4th of May, the pulsation still existing in the tumour, but the patient was not much inconvenienced by it. I watched him occasionally up to the present time, January the 14th, 1838. The tumour has gradually, with the pulsation, subsided, and he is now perfectly well, and nearly as well able to follow his former occupation as before. Neither pulsation or tumour exists in either ham, and he says that he can carry a sack of flour as well as ever, except that he finds some weakness in going up stairs. I should here acknowledge the kindness of $\mathrm{Mr}$. Lawrence, of Lon. don, and Mr. Hodgson, of Birmingliam, with whom I corresponded respecting this case (to me both interesting and novel), and received the valuable suggestions and advice of those gentlemen.

\section{RECLAMATION OF MR. NEWPORT.}

\section{To the Editor of THE LANCET.}

SIR:-I observe in the last number of The Lancet (Feb. 3), some statements in Dr. Hall's lecture on the "Nervous System," page 650 , paragraphs 15 and 16 , which cannot apply to any one but myself, since I am the only one of Professor Crrant's pupils who attended his course on "Comparative Anatomy," in the session 1832-33, and who since that period has published a detailed account of distinct motor and sensitive columns in the nervous system of articulated animals. I beg to express my surprise at those statements, which, to say the least of them, are decided misrepresentations, there being in the first of these paragraphs a suppression of facts, which Dr. Hall himself cannot be unacquainted with; and, in the second, a statement that leads to an inference which is not correct, namely, that Professor Grant taught the doctrine of the existence of distinct motor and sensitive columns in the nervous system of articulated animals at that time as his own. In doing this Dr. Hall appears to be rendering Professor Grant great disservice, in thus endeavouring to make it appear to the public that he lays claim to my discovery of the true motor aud sensitive columns in these animals; and I cannot suppose that Professor Grant is either so unjast, or so inconsistent, as to do so, since there are circumstances which, if made known, would, I trust, sufficiently prove nnto whom this discovery really does belong. In conclusion, I would also observe, that there are other passages in Dr. Hall's lecture, which are not in so strict an accordance with facts as $I$ should have supposed Dr. Hall would have considered necessary to his character, as an honourable cultivator of science. I remain, Six, your obedient servant,

10, University-street,

Georae Neifrort. Feb. 6, 1838.

P.S. In the meantime $I$ beg to refer your readers to my two papers on the Nervous System of Insects, published in the "s Philosophical Transactions" for the year 1832 and 1834, Parts II., in each year.,

CASE OF THE

\section{PUERPERAL-MANIA PRISONER.}

\section{To the Editor of The LanceT.}

SIR :-I may, I trust, be allowed space in your valuable Journal, to answer the very uncourteous, and, as the event has proved, rather hasty attack made upon me, in a letter in The Lancet of last week, signed " $A$ Member of the Legal Profession," in answer to a former communication of mine.

It is a pity that the writer did not wait one little week, ere he commented in such unmeasured terms, upon my letter. Alas for the fallacy of his judgment! the jury at the Central Criminal Court, on the woman's trial, January 31st, brought in a verdict of " Not guilty, on the ground that at the time the act was conmitted, the prisoner was labouring under temporary derangement." It is evident that your "legal" correspondent, in his haste to take up the cudgels for the Coroner, has altogether misunderstood my letter. Although no lawyer, I humbly conceive that the duties of a coroner's jury and a grand jury, are not so perfectly identical as to warrant the sweeping inference which your "legal" correspondent draws therefrom. He says that, because the Judge required the Grand Jury to return a true bill, it is "clearly shown that the Coroner was right in his direction to the Jury, the very same direction having been given by Mr. Baron Alderson, the Judge presiding in the Central Criminul Court." Audialteram partem. "The Coroner, in summing up, observed that no doubt a jury in another court, would, upon the evidence, take a merciful consideration of the case, and judge the poor woman to be confined as a lunatic for life." I leave to your readers to find the parity between these. That the Coroner was wrong in his directions (and it was to this point my strictures were chiefly directed) is clearly proved by the Jury, on the poor woman's trial, acquitting her, on the ground of temporary derangement,-the object to prove which I strove. We all know, albeit not "members of the legal profession," 